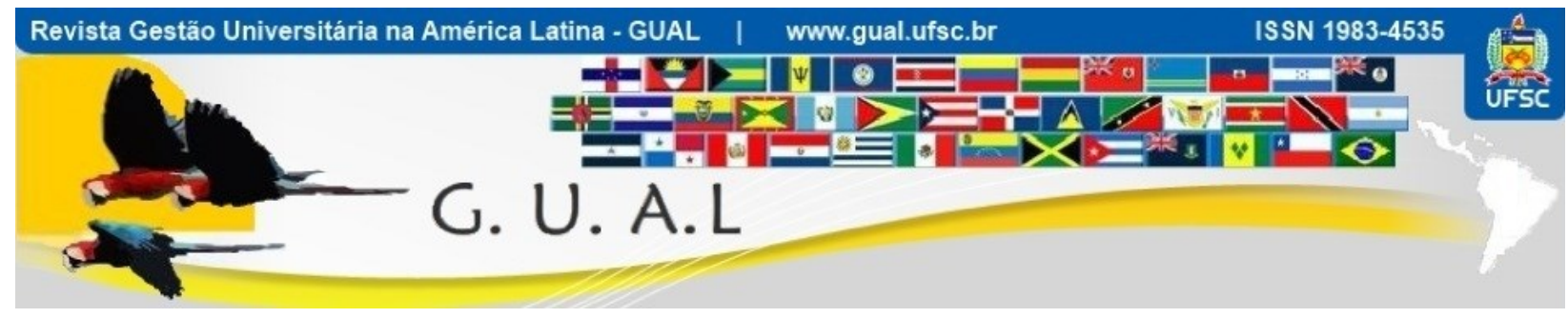

DOI: http://dx.doi.org/10.5007/1983-4535.2016v9n2p131

\title{
OS DILEMAS DA GESTÃO DE UNIVERSIDADES MULTICAMPI NO BRASIL
}

THE DILEMMA OF MANAGEMENT OF UNIVERSITIES MULTICAMPI IN BRAZIL

Egeslaine de Nez, Doutora Universidade do Estado de Mato Grosso - UNEMAT egeslaine@unemat.br

Recebido em 30/junho/2014

Aprovado em 29/janeiro/2016

Sistema de Avaliação: Double Blind Review

Esta obra está sob uma Licença Creative Commons Atribuição-Uso. 


\title{
RESUMO
}

Esse estudo objetiva compreender os dilemas da gestão do modelo de instituições universitárias multicampi, levando em consideração que o cenário brasileiro permitiu um desenho organizacional diferenciado para atender as regiões. Pretende-se identificar as dificuldades vivenciadas por esse modelo, aproveitando a experiência de três décadas de existência da Universidade do Estado de Mato Grosso (Unemat), que possui treze campi e dez núcleos pedagógicos, indicando caminhos alternativos para superação dos entraves. Num primeiro momento, o procedimento metodológico foi o levantamento bibliográfico que consistiu num estado de conhecimento/estado da arte sobre a terminologia multicampi. Foi utilizada também uma pesquisa documental sobre os anuários e catálogos institucionais relativos aos desdobramentos da temática em estudo. Posteriormente realizou-se uma pesquisa de campo com entrevistas aplicadas a cinco ex-pró-reitores de pesquisa e pós-graduação da Unemat, além de vinte e um líderes de grupos de pesquisa, constituindo um estudo de caso. A abordagem analítica de reflexão dos dados foi a análise de conteúdo e a pesquisa quali/quantitativa. Diante dos resultados obtidos, constatou-se que a proposta multicampi se expande em unidades menores tentando não comprometer a identidade institucional. Pode-se, considerar finalmente, que existem vantagens na multicampia, entretanto, a dispersão geográfica cria dificuldades de natureza administrativa.

Palavras-chave: Educação superior. Modelo universitário. Gestão.

\begin{abstract}
This research aims to understand the dilemmas of managing the universities multicampi model taking into account that the Brazilian scenario allowed a differentiated model to meet the regions. It is intended to identify the difficulties experienced by this model, drawing on the experience of three decades of existence of the State University of Mato Grosso (Unemat), who has thirteen campus and ten pedagogical cores, indicating alternative ways to overcome obstacles. At first, the methodological procedure was the bibliographic research which consisted in a state of knowledge/state of the art on multicampi terminology. Documentary research on institutional directories and catalogs relating to the topic under study was also used. Later there was a research field applied to five interviews with former pro-rectors for research and post-graduate of the Unemat, besides twenty-one leaders of research groups, providing a depth case study. The approach of reflection data was content analysis and research qualitative/quantitative. Based on these results, it was found that the proposed multicampi expands into smaller units trying not to compromise the institutional identity. You can finally consider that there are advantages in multicampia, however, the geographical dispersion creates administrative difficulties and especially management.
\end{abstract}

Key Words: Higher education. Model university. Management. 


\title{
1 INTRODUÇÃO
}

\begin{abstract}
Sete preconceitos antigos sobre a educação superior:
$1^{\circ}$ Preconceito: A educação superior deve ser para uma elite e não para as massas.

$2^{\circ}$ Preconceito: A educação superior diminui a qualidade conforme se divide com uma maior numero de gente.

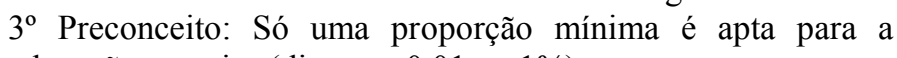
educação superior (digamos 0,01 ou 1\%).

$4^{\circ}$ Preconceito: Para a educação superior se devem selecionar os mais aptos.

$5^{\circ}$ Preconceito: Não se deve proporcionar educação superior além das possibilidades de emprego.

$6^{\circ}$ Preconceito: O Estado já está gastando demasiado em educação superior. A educação superior não deve ser gratuita ou semigratuita.

$7^{\circ}$ Preconceito: Não se deve querer que todos sejam profissionais. Seria horrível um mundo em que não houvesse operários. (CASANOVA apud WANDERLEY, 1984, p. 6).
\end{abstract}

A sociedade contemporânea modifica-se num ritmo alucinante. Vive-se, hoje, em apenas uma década, transformações profundas que afetam o cotidiano de modo acentuado. Pretto (2000) esclarece que este momento é demarcado por tendências de ordem econômica, cultural e social que geram desafios e interferem no destino das nações. A transnacionalização econômica e as propostas hipermodernas ${ }^{1}$ de cultura, além dos movimentos sociais em busca de espaço, recorrem à Educação e veem nela um meio para atingir seus objetivos finalísticos.

Para Silva e Gentili (1996) a Educação veiculada como produto, bem ou serviço, converte-se no alicerce de uma sociedade que se reporta ao conhecimento (DIDRIKSSON, 2008). Neste contexto, o presente trabalho tem como objetivo a pertinência da tendência de valorização da Educação e do conhecimento, ressaltando a temática da gestão das universidades multicampi e de seus desdobramentos num universo de franca expansão na Educação Superior brasileira.

A universidade encontra-se num emaranhado onde também se desponta a sociedade organizada em rede (CASTELLS, 2001) que traz em seu bojo o paradoxo provocado pela hipermodernidade. Embora cumpra suas funções de ensino, de pesquisa e de extensão, diferencia-se das demais instituições, pelo seu tipo de atividade e pelo seu papel desempenhado. Desse modo, tem importância basilar na construção da sociedade contemporânea, ressaltando um compromisso com o passado na preservação da memória; com o presente na geração, sistematização, disseminação do conhecimento e na formação dos

\footnotetext{
${ }^{1}$ A hipermodernidade é um termo cunhado por Lipovetsky (2004) que representa uma sociedade caracterizada pelo movimento, pela fluidez e pela flexibilidade. Tudo acontece rapidamente como se tivesse ido do pós para o hipermoderno, gerando um tipo diferenciado de sociedade.
} 
profissionais; e com o futuro na prospecção do desenvolvimento social (NEZ, 2014). Porém, não pode permanecer isolada e à margem das vertiginosas mudanças que acontecem no espaço que a circunda e no qual interfere decisivamente com suas ações.

Para Chauí (2001), enquanto instituição histórica, a universidade está enraizada em situações concretas que balizam os tempos e suas relações com o contexto sócio-econômico sempre estão atravessadas por contradições diversas. Tanto é desta forma que se pode observar no seu interior opiniões, atitudes e projetos conflitantes que exprimem as dicotomias da sociedade.

Há uma tendência de identificar a universidade como ambígua por natureza porque a própria sociedade que atende, também é. Nez (2014) comenta que há interesses profundamente diferentes sobre as funções da universidade e essas divergências tornam-se acentuadas quando se evidenciam as contradições atuais. Porém, é importante insistir que as Instituições de Educação Superior (IES) são dinâmicas e devem se transformar junto com as mudanças que ocorrem na sociedade, na cultura, na política e na economia.

Entretanto, existe uma nítida concepção entre os envolvidos na Educação Superior, de que a universidade é o lugar privilegiado para o acesso à cultura universal e a ciência, para criar e divulgar o saber científico. Chauí (2001) considera que a universidade é uma instituição social com uma prática social fundada no reconhecimento público de sua legitimidade e de suas atribuições, que lhe confere autonomia perante outras instituições.

No Brasil, desde a década de oitenta, os movimentos sociais passaram a lutar pela democratização e melhoria na oferta da Educação Superior. Nos últimos anos, houve uma expansão das universidades brasileiras que foi perceptível no quantitativo de vagas oferecidas (NEVES, 2012) e, que, segundo Nez e Silva (2012b) também foi proporcionado pelo Programa de Reestruturação e Expansão das Universidades Federais (REUNI). Nesta conjuntura, algumas IES surgiram alternativamente com uma estrutura diferenciada para a ampliação do sistema, são as instituições multicampi.

Essa pesquisa objetivou compreender os dilemas da gestão do modelo de instituições universitárias multicampi, levando em conta que o cenário brasileiro permitiu esse desenho organizacional para o atendimento de uma demanda reprimida. Pretendeu-se, desta forma, identificar as dificuldades vivenciadas nesse modelo institucional, aproveitando a experiência de três décadas de existência da Unemat, que possui treze campi, dez núcleos pedagógicos, seis pólos de ensino a distância e cerca de quinze mil acadêmicos, com vistas à substanciar alternativas para superação dos entraves. 
A relevância científica deste estudo é marcante, pois seu escopo identifica que as instituições escolheram o modelo multicampi para suprir lacunas no acesso à Educação Superior em algumas regiões brasileiras, porém trouxeram algumas dificuldades imanentes à dispersão geográfica. Nesta direção, este artigo se encontra disposto em cinco eixos além dessas notas introdutórias: o primeiro indica as reflexões de cunho metodológico; em seguida, explicitam-se os conceitos teóricos da multicampia; posteriormente, apresenta-se o estudo de caso da Unemat; no quarto eixo os resultados e as discussões da pesquisa de campo; e, por fim, no quinto eixo se sinalizam as considerações finais retomando o objetivo proposto pela investigação.

\title{
2 PROCEDIMENTOS METODOLÓGICOS
}

\begin{abstract}
Quem olha de fora, através de uma janela aberta, não vê jamais tantas coisas quanto quem olha uma janela fechada. Não há objeto mais profundo, mais misterioso, mais fecundo, mais tenebroso, mais deslumbrante do que uma janela iluminada por uma vela. $\mathrm{O}$ que se pode ver à luz do sol é sempre menos interessantes do que o que se passa atrás de uma vidraça. Nesse buraco negro ou luminoso vive a vida, sonha a vida, sofre a vida. (BAUDELAIRE apud BOURDIEU, 2011, p. 13).
\end{abstract}

Esta investigação ora apresentada fundamentou-se na interlocução com a realidade educacional mato-grossense e no levantamento de hipóteses que visavam aprofundar estudos sobre a questão da multicampia, evidenciando a emergência desse modelo nas universidades brasileiras. A estratégia metodológica utilizada organizou-se a partir de uma rede de pressupostos que definiram a concepção de universidade que perpassou o problema. Nez (2014) acredita que esses pressupostos proporcionaram as bases da pesquisa, fazendo com que o mundo pudesse ser interpretado sob determinada perspectiva e que alguns elementos contribuiriam na busca de uma leitura não ingênua, mas crítica da gestão de IES multicampi.

Incialmente, o procedimento utilizado foi a pesquisa bibliográfica. Na prática, o estudo não existiria sem uma revisão aguda da literatura, que a situa numa tradição teórica, a qual tem sua história feita de rupturas, isso gerou um estado de conhecimento/estado da arte $^{2}$ acerca da temática multicampi. Num segundo momento, foi realizada uma pesquisa documental e uma pesquisa de campo, o instrumento de coleta de dados escolhido foi a

\footnotetext{
2 "São produções acadêmicas que sintetizam um dado número de estudos, selecionados sob critério(s) previamente estabelecido(s), sobre uma temática ou um recorte específico. A matéria-prima para tais estudos pode ser bancos de resumos, produções para uma conferência, revisões de uma temática em periódicos científicos, entre outros exemplos" (FRANCO, 2011, p. 152). Alguns autores a intitulam de estado da arte, tais como: Fávero e Oliveira (2012) e Morosini (2006).
} 
entrevista, na tentativa de compreender as dificuldades na gestão multicampi que atende a uma grande faixa territorial em sua estrutura.

Sobre a amostra, destaca-se que não se constituiu por acaso, mas em função de características específicas de intencionalidade (líderes de grupos de pesquisa e pró-reitores de pesquisa e pós-graduação da IES). Os primeiros porque se tratam de pesquisadores tem de algum modo envolvimento aprofundado nas atividades universitárias. Já a segunda categoria de entrevistados trazem em relevo que em algum momento da história da Unemat fizeram parte da gestão no cargo de Pró-reitor de Pesquisa e Pós-graduação e puderam vivenciar a realidade discutida nesse estudo. Foram entrevistados cinco ex-pró-reitores (recorte temporal: 1994 a 2012) e vinte e um líderes de grupos de pesquisa de oito campi.

Com relação à reflexão analítica, foram utilizadas as seguintes abordagens: análise de conteúdo (BARDIN, 1977, GUERRA, 2008 e FRANCO, 2008) e abordagem quanti/qualitativa (GAMBOA, 1995). A opção metodológica de se apreciar os dados a partir da primeira abordagem é evidenciada porque sua utilização, enquanto procedimento, reconhece o papel ativo do sujeito na produção do conhecimento.

Especificamente sobre a metodologia quali/quantitativa, muitas são as divergências observadas sobre sua utilização, porém a proposta desta pesquisa foi o uso conjugado que se mostrou adequado na construção de uma análise crítica da complexa realidade desta IES do Estado de Mato Grosso. Assim, aceitou-se o pressuposto de Gamboa (1995) da terceira reação, que concebe as condições de produção da investigação, propondo a síntese e a superação de falsos dualismos e dicotomias epistemológicas. "Busca-se a objetividade processual e a correção dos desequilíbrios oriundos dos radicalismos, aceitando a produção do conhecimento como realidade socialmente construída" (p. 89).

Partindo dessa premissa, elegeu-se a pesquisa quanti/qualitativa como uma das formas apropriadas no tratamento dos dados uma vez que permitiu a abertura, a recorrência entre o referencial teórico, a pesquisa documental e as entrevistas contribuindo para uma visão global do estudo de caso desta IES de Mato Grosso na região central do País.

\section{EXPLICITANDO O CONCEITO MULTICAMPI}

Uma vez assumida a existência da Universidade multicampi, que tem característica de equidade, esse modelo se destaca por desempenhar um importante papel de desenvolvimento regional. Tornam-se assim pertinentes e relevantes os estudos sobre sua relação com a sociedade com esta proposta. (BAMPI e DIEL, 2013, p. 02). 
A universidade está passando por mudanças tanto na estrutura quanto na sua posição social, demandas desta atual sociedade que lhe imprime novos contornos e desafios. Zabalza (2004) comenta que essa dinâmica de adaptação constante acelerou-se nesse último meio século e que é impossível um ajuste adequado sem uma transformação profunda dos fundamentos internos da universidade.

Nos últimos quarenta anos, a universidade vem se recriando. Historicamente, destacase que houve um rápido aumento do número de matrículas nas décadas de sessenta e setenta, e, segundo Nez e Silva (2012a) depois de um período de estagnação, esse número praticamente dobrou. Embora essa ampliação possa ser atribuída ao crescimento das instituições privadas, a contribuição significativa das universidades públicas estaduais não pode ser desconsiderada. Para Cabral Neto (2006, p, 50) "O aumento da demanda por educação superior decorre, dentre outros fatores, da universalização do ensino fundamental e do incremento da matrícula no ensino médio verificada nos últimos anos da década de 1990".

Uma das ações que potencializou o acréscimo das vagas e alavancou a democratização da Educação Superior foi o REUNI que congregou esforços para a consolidação de uma política nacional de expansão da rede pública brasileira (BRASIL, 2012). Além de proporcionar uma reorganização da oferta, utilizou-se juntamente de outra ações, entre elas, o modelo multicampi para oportunizar crescimento quantitativo das vagas e atendimento para várias regiões brasileiras.

Nesse contexto, destaca-se a introdução do fenômeno organizacional multicampi nas instituições federais, mas que já vinha sendo utilizado predominante nas universidades públicas estaduais e em algumas instituições privadas no Brasil. Fialho (2005) considera que este modelo experimentado nos Estados Unidos, permitiu uma penetração em áreas geograficamente dispersas, promovendo o acesso a populações excluídas e contribuiu para a modernização do sistema americano de Educação Superior.

$\mathrm{Na}$ perspectiva vernácula, a palavra multicampi se compõe da partícula multi (latim multus) que corresponde a muitos; adicionada a campus (latim) palavra masculina da segunda declinação, que significa o conjunto de edifícios e terrenos de uma IES. No dicionário, sua definição remete quase que exclusivamente à quantidade. Multicampi resulta, então, do normativo plural da palavra campus associada ao adjetivo para designar o termo "muitos campos" que representaria a diversidade de espaços (HOUAISS e VILLAR, 2009).

Num sentido restrito, campus é um espaço delimitado e exclusivo que pode estar situado em qualquer lugar dentro ou fora da universidade. Para Cunha (1998) a ideia-limite 
consiste no território que reúne as instalações de uma IES. Mas o conceito comporta uma significação ampliada, o sentido acadêmico: lócus da produção intelectual. Com o tempo, a palavra perdeu este significado em substituição a ideia de localização geográfica. A partir dos anos sessenta, acentua-se o significado de distanciamento em relação aos centros urbanos.

Buarque (1994) corrobora com essa explicitação quando discute que os elementos implícitos na sua conceituação são manifestos em duas acepções: física-espacial (assentamento de uma estrutura que indica o distanciamento) e acadêmica (localização de um espaço da produção intelectual).

Lauxen (2006) destaca que o termo multicampi remete a uma concepção de universidade com uma estrutura organizacional distribuída em vários espaços geográficos. Isso sinaliza a existência de unidades com pólos de ação situados em contextos físicoterritoriais diferentes que atendem aos interesses das regiões em que atuam.

Para Fialho (2005) esse modelo é uma forma consagrada que não se prende a um único espaço geográfico. Entretanto, também constata que a designação faz supor algo mais do que a simples referência ao número de campus ou sua localização territorial. Ou seja, o sentido de organicidade se torna basilar em sua configuração. Fialho (2005) ainda expõe que é “[...] um tipo de instituição universitária que, refletindo-se nas dimensões acadêmicas, organizacionais e espaciais, se traduz segundo uma morfologia composta por muitos campi" (p. 27).

Com essa configuração a função da universidade está implícita nas dimensões históricas, políticas, sociais e educacionais dos processos de organização das sociedades e de produção do conhecimento científico.

Essa expressão (multicampi), portanto, cujos significados nem sequer se encontram absorvidos pela língua vernácula, embora já consagrada para dizer de uma modalidade de ensino superior, vai além do mero ato de designar alguma coisa: ela aponta para um fenômeno que se pretende diferenciado de outros, a exemplo dos modelos universitários cuja configuração não se restringe a um único lugar enquanto localização física [...] (FIALHO, 2005, p. 51 - grifos da autora).

Boaventura (1987) também esclarece que a importância na constituição de uma universidade multicampi é a sua marca regional, isto é, "a formação de campus se dá a partir de características profundamente regionais" (p. 32). Deste modo, essas instituições não podem ser definidas apenas por seu modelo organizacional, mas concomitantemente pela sua inserção geográfica regional. Compreender isso, não é mera questão semântica, vai além desvelando a questão epistemológica do termo. 
Sinteticamente, pode-se considerar que as instituições multicampi são caracterizadas pela ampla cobertura no território estadual mediante a sua presença em um significativo número de municípios. Contudo, há ainda uma reflexão importante,

[...] é fundamental compreender que a organização universitária multicampi planta, concretamente, no espaço físico-geográfico, no território, unidades encarregadas do cumprimento das finalidades estatuárias da instituição (unidades que integram os chamados campi universitários) e que estas unidades se encontram, também, encarregadas da realização da missão universitária, num contexto de convivência com realidades regionais bastante diferenciadas (FIALHO, 2005, p. 67).

Lauxen (2006) expõe que as IES multicampi favorecem a interiorização da Educação Superior, pois cada campi se torna a certo modo a sede da universidade. Devem, então possuir características administrativas próprias e autonomia de recursos, bem como de particularidades acadêmico-científicas, de modo a integrarem-se e relacionar-se intensamente com o contexto regional que está inserida.

Todo esse estado de conhecimento revela que as posturas teóricas sobre o conceito permitem evidenciar reflexões acerca da trajetória de sentidos atribuídos à palavra multicampi, que foram/são: quantidade, localização geográfica, e lugar da produção científica. Isso proporciona um encontro das dimensões relativas à estrutura organizacional e a dispersão físico-territorial para categorizar uma instituição com essa amplitude.

Finalmente, deve-se considerar ainda o que Nez e Silva (2012b) explicitam que é a magnitude desse fenômeno expansionista que representou no final da década de noventa, $80 \%$ das universidades estaduais espalhadas no território nacional. Para Fialho (2005) esses resultados confirmam a expressividade de um fato que se manifestou tanto pelo quantitativo das universidades multicampi quanto pela abrangência da distribuição territorial.

Todavia, Fialho (2005) expõe que há desvantagens, já que “a dispersão geográfica de unidades institucionais cria dificuldades de natureza administrativa e de gestão acadêmica. Emergem problemas referentes à construção de uma identidade orgânica da instituição, com reflexos negativos no seu desempenho" (p. 13). E ainda, ressalta que a configuração multicampi nem sempre é contemplada nas políticas governamentais e nos processos de planejamento, mesmo que as IES com essa natureza comportem uma relação profícua com seu contexto urbano e regional.

\section{CONTEXTO DA INVESTIGAÇÃO}

A pesquisa como investigação de algo, nos lança na interrogação, pede reflexão, crítica, enfrentamento com o 
instituído, descoberta, invenção e criação. É um trabalho do pensamento e da linguagem para pensar e dizer o que ainda não foi pensado nem dito, uma visão compreensiva de totalidades, ação civilizatória contra a barbárie social e política, onde a reflexão, a crítica, o exame de conhecimentos instituídos, possibilita sua mudança e sua superação. (CHAUI, 2001, p. 222 - grifo meu).

Esse etudo foi desenvolvid na Unemat, que está inserida em Mato Grosso há trinta e sete anos, com sede em Cáceres, no Pantanal mato-grossense, na margem esquerda do rio Paraguai. Para Zattar (2008) teve uma trajetória dedicada à formação de professores da Educação Básica da região centro-oeste do país. A IES está distribuída geograficamente nas doze macrorregiões do Mato Grosso definidas na Política $\mathrm{MT}+20^{3}$, levando aos mais longínquos lugares, oportunidade de acesso ao conhecimento.

Segundo dados do Anuário Estatístico (2012), a Unemat está presente em cento e dezessete dos cento e quarenta e um municípios mato-grossenses, com treze campi, dez núcleos pedagógicos e seis pólos de ensino a distância. Os campi universitários são: Cáceres (sede), Alta Floresta, Alto Araguaia, Barra do Bugres, Colider, Diamantino, Juara, Luciara, Nova Mutum, Nova Xavantina, Pontes e Lacerda, Sinop e Tangará da Serra, e atendem a todas as regiões do Estado. Só para se ter ideia da extensão envolvida, há uma diferença geográfica enorme. Pode-se usar como referência a sede que está localizada em Cáceres e o campus que se encontra mais ao norte do Estado que é Alta Floresta. A distância é de aproximadamente $1.000 \mathrm{~km}$. Para vencer as barreiras geográficas impostas pela gigantesca extensão territorial, a IES se utiliza de uma estrutura multicampi.

Com relação aos núcleos, consistem em espaços administrativos e pedagógicos para a oferta de modalidades diferenciadas de ensino, cuja estrutura e organização são provisórias. Neles, segundo Machado Cunha (2010), os cursos possuem organizações curriculares adaptadas às necessidades propostas por convênios com prefeituras.

Até 1990, a Unemat, na época denominada Fundação Centro de Ensino Superior de Cáceres (FCESC), possuía apenas dois cursos de Licenciatura Plena (Letras e Pedagogia) e dois de Licenciatura Curta (Ciências e Estudos Sociais). Zattar (2008) esclarece que com a ampliação do sistema local e regional, surgiram novas escolas de Ensino Fundamental e Médio, indicando a necessidade de contratação de profissionais habilitados para atuarem nas diversas áreas do conhecimento. Foram criados, posteriormente, outros cursos para atender

\footnotetext{
${ }^{3}$ Este é o Plano de Desenvolvimento do Estado de Mato Grosso, que aponta conceitos básicos sobre o incremento sustentável e o planejamento participativo, com vistas aos cenários futuros de sua atuação. Ver mais sobre em: http://www.unemat.br/prpdi/pdi/docs/mt 20 parte 4.pdf (PLANO, 2013).
} 
essa demanda. Desta forma, com a inclinação de uma "universidade do interior voltada para o interior", a Unemat direcionou suas atividades de ensino, de pesquisa e de extensão para todas as áreas do conhecimento.

A estrutura multicampi começou a ser instalada a partir da década de 90, e a ideia de uma universidade pública que atendesse todo o Estado foi se concretizando. Zattar (2008) comenta que essa expansão intensificou-se com a criação das unidades em Barra do Bugres, Tangará da Serra, Colider e Juara. Quanto a esse processo verificar quadro a seguir:

\begin{tabular}{|c|c|}
\hline ANO & CAMPUS \\
\hline 1978 & Cáceres \\
\hline 1990 & Sinop \\
\hline $1991 / 1992$ & $\begin{array}{c}\text { Alta Floresta } \\
\text { Alto Araguaia } \\
\text { Luciara } \\
\text { Nova Xavantina } \\
\text { Pontes e Lacerda }\end{array}$ \\
\hline 1994 & $\begin{array}{c}\text { Barra do Bugres } \\
\text { Colider }\end{array}$ \\
\hline 1995 & Tangará da Serra \\
\hline $1999 / 2003$ & Juara \\
\hline 2013 & $\begin{array}{c}\text { Diamantino } \\
\text { Nova Mutum }\end{array}$ \\
\hline
\end{tabular}

Quadro 01 Expansão dos campi universitários Fonte: Nez (2014).

É nesse cenário expansionista, que a Unemat se firmou como uma instituição de formação de licenciados e bacharéis. Salienta-se que os resultados da política de promoção de Educação Superior estadual em diferentes regiões do Estado identificou uma mostra significativa da importância da interiorização dessa IES. Frente a esses elementos analíticos, observa-se que sua criação foi um projeto não somente técnico-científico e cultural, mas ideológico, resultado da tomada de consciência da realidade regional.

Sobre a oferta de Educação Superior em Mato Grosso, o Anuário Estatístico (2012) informa que cerca de treze mil e setecentos acadêmicos são atendidos em sessenta e nove cursos de graduação, quarenta e quatro regulares que estão distribuídos em licenciaturas e bacharelados que atendem às demandas do Estado e sua inserção regional. As modalidades diferenciadas são programas como Licenciaturas Plenas Parceladas ${ }^{4}$, Universidade Aberta do Brasil (UAB), Educação do Campo, Terceiro Grau Indígena ${ }^{5}$ e Turmas Fora de Sede ${ }^{6}$.

\footnotetext{
${ }^{4}$ São cursos de formação em serviço e continuada que são ofertados no interior do Estado, exclusivamente para professores em exercício do magistério (ZATTAR, 2008).

${ }^{5}$ Tem como objetivo a formação de professores indígenas para o exercício docente no Ensino Fundamental e Médio, nas escolas das aldeias (ZATTAR, TAVARES e ARTIOLI, 2010).
} 
Segundo o Plano de desenvolvimento institucional 2008/2014 (2008), como instituição pública de oferta de Educação Superior em Mato Grosso, a IES tem como compromisso o atendimento das necessidades das comunidades onde está inserida. Isto se assenta na justificativa de que para algumas regiões geoeducacionais, é a única possibilidade para alunos do Ensino Médio e Profissionalizante, que sem a qualificação necessária não conseguem continuar seus estudos noutros centros. Infere-se que levando em conta a carência da população por Educação Superior, essa IES atendeu ao longo dos anos a um número relativamente expressivo de acadêmicos, porém as dificuldades oriundas desse modelo, tais como, a distância entre os campi, entre outros elementos que se constituem em barreiras à gestão universitária.

No âmbito da Pós-graduação, segundo anuário (2012), a Unemat oferece em nível Lato Sensu, vinte e quatro cursos, além de dez Programas Stricto Sensu de Mestrados e dois Doutorados Institucionais para a composição de seu espaço de produção do conhecimento, veja quadro que segue:

\begin{tabular}{|c|c|c|c|c|}
\hline NR. & PROGRAMA & CAMPUS & $\begin{array}{l}\text { CONCEITO } \\
\text { CAPES }\end{array}$ & CRIAÇÃO \\
\hline 01 & Mestrado em Ciências Ambientais & Cáceres & 4 & 2006 \\
\hline 02 & $\begin{array}{l}\text { Mestrado e Doutorado em Ecologia e } \\
\text { Conservação }\end{array}$ & Nova Xavantina & 4 & $\begin{array}{l}2008 / \\
2015\end{array}$ \\
\hline 03 & Mestrado em Linguística & Cáceres & 3 & 2010 \\
\hline 04 & $\begin{array}{lllll}\begin{array}{l}\text { Mestrado } \\
\text { Literários }\end{array} & \text { D } & \text { Doutorado } & \text { em } & \text { Estudos } \\
\end{array}$ & Tangará da Serra & 4 & $\begin{array}{l}2010 / \\
2013\end{array}$ \\
\hline 05 & Mestrado em Educação & Cáceres & 3 & 2010 \\
\hline 06 & $\begin{array}{l}\text { Mestrado em Ambiente e Sistema de } \\
\text { Produção Agrícola }\end{array}$ & Tangará da Serra & 3 & 2011 \\
\hline 07 & $\begin{array}{l}\text { Mestrado em Genética e Melhoramento de } \\
\text { Plantas }\end{array}$ & $\begin{array}{l}\text { Cáceres } \\
\text { Tangará da Serra } \\
\text { Alta Floresta }\end{array}$ & 4 & 2012 \\
\hline 08 & $\begin{array}{l}\text { Mestrado em Biodiversidade } \\
\text { Agroecossistemas Amazônicos }\end{array}$ & Alta Floresta & 3 & 2012 \\
\hline 09 & $\begin{array}{l}\text { Mestrado em Ensino de Ciências } \mathrm{e} \\
\text { Matemática }\end{array}$ & Barra do Bugres & 3 & 2015 \\
\hline 10 & Mestrado em Geografia & Cáceres & 3 & 2015 \\
\hline
\end{tabular}

Quadro 02 Programas de Pós-graduação Stricto Sensu Fonte: Nez (2014).

Essas são ações pioneiras do Estado para atender às demandas regionais e constituem frentes de trabalho que fazem suas atividades responsáveis e conscientes, isso possibilita o pleno cumprimento de sua função social e constitucional. Segundo Zattar, Tavares e Artioli

\footnotetext{
${ }^{6}$ Cursos regulares que são ofertados para atender às demandas específicas nos municípios que não possuem Educação Superior (ZATTAR, TAVARES e ARTIOLI, 2010).
} 
(2010), no contexto regional, a instituição atua na formação de professores e bacharéis, nas diferentes áreas do saber, na construção da cidadania e no desenvolvimento de Mato Grosso.

Desta forma, ao longo dos trinta e sete anos de funcionamento, a Unemat representou para a população mato-grossense, um conjunto de experiências didático-científicopedagógicas e administrativas, que a projetou como uma instituição portadora de requisitos indispensáveis ao desenvolvimento do ensino, pesquisa e extensão. Desempenhou, assim, um papel social, capaz de alicerçar a base humana regional na afirmação de melhores condições de vida da população (HISTÓRICO, 2011).

A lógica das universidades multicampi, e aqui no caso da Unemat, foi a expansão em unidades sem perder sua identidade institucional. Fialho (2005) destaca que essa estratégia produz dois elementos estruturantes: a organização acadêmica de base; e a dimensão regional no atendimento à necessidade de Educação Superior. Um dos líderes de grupos de pesquisa (LG15) entrevistado corrobora com essa explicitação quando indica que a estrutura da Unemat foi criada a partir de dois focos. Um deles foi a oportunidade de desenvolvimento local e regional do Estado, através da organização do acesso à Educação Superior. O outro diz respeito, especificamente, à distância física dos grandes centros urbanos. Para o respondente, “essa estrutura é algo fantástico, isto porque ser multicampi significar ser multinucleada, entendida como estruturas fixas temporárias para as atividades".

Para os gestores, segundo o LG15, ficam os desafios para organizar essa instituição buscando "encurtar os caminhos, dar acesso aos lugares que não tem nenhuma oferta e nenhuma oportunidade". Desta forma, a institucionalidade multicampi de um lado dá origem à multidiversidade espacial dos seus campi e de outro, singulariza o contexto a que dá origem, através da expansão. Fialho (2005) destaca que a universidade multicampi

[...] não é só universidade, entendida enquanto organização, não é só contexto, entendido como dispersão regional e urbana, e nem é uma combinação articulada desses dois termos, ou seja, é algo que não se faz presente em nenhum deles, isoladamente tomados. Modelo e contexto entrelaçam-se, um sendo constitutivo do outro, um sendo produto do outro (p. 115).

Em sendo deste modo, esse modelo tanto promove como age, interage e reage às condições de desenvolvimento regional e local. A multicampia potencializa a diversidade, pois, segundo Nez e Silva (2012a) o campus está em contato com realidades distintas, visto que a Unemat não é um fenômeno social isento das condições sociais, é, então, um produto que se traduz numa forma organizacional que se concretiza num determinado espaço. 


\section{OS DADOS IDENTIFICARAM QUE...}

Não nego, de modo algum, que outras tendências e objetivos permeiam o cotidiano da vida universitária, tecido colorido de ideais edificantes e esdrúxulos. Pretendo apenas salientar os obstáculos que travam o jogo universitário e igualmente indicar como as forças internas de mudança não tendem a reforçá-lo ou a regenerá-lo, tornando-se empecilhos ao seu restabelecimento. Desenhar uma universidade ideal e tentar implantá-la sem levar em conta os impulsos negativos gerados por esse intento é cair no voluntarismo mais inócuo. (GIANOTTI, 1986, p. 66 - grifo meu).

Neste estudo de caso, o instrumento de coleta de dados foi uma entrevista realizada in loco com líderes de grupos de pesquisa em vários campi da IES para identificar as dificuldades existentes no deslocamento entre as unidades acadêmicas. Além disso, na tentativa de compreender o processo de gestão de uma universidade com modelo multicampi, foram contatados cinco ex-Pró-reitores de Pesquisa e Pós-graduação na sede (Cáceres). Conforme já salientado, a Unemat atende a uma grande faixa territorial envolvendo enormes distâncias.

No total vinte e um líderes foram entrevistados, sua distribuição por campus pode ser visualizada a seguir:

Tabela 01 Distribuição da amostra por campi universitário

\begin{tabular}{l|c|c}
\hline \multicolumn{1}{c|}{$\boldsymbol{C A M P U S}$} & $\begin{array}{c}\text { QUANTIDADE DE } \\
\text { ENTREVISTADOS }\end{array}$ & $\begin{array}{c}\text { PORCENTAGEM } \\
(\boldsymbol{\%})\end{array}$ \\
\hline Cáceres (sede) & 07 & 33,33 \\
\hline Barra do Bugres & 04 & 19,11 \\
\hline Nova Xavantina & 03 & 14,26 \\
\hline Sinop & 03 & 14,26 \\
\hline Alta Floresta & 01 & 4,76 \\
\hline Alto Araguaia & 01 & 4,76 \\
\hline Tangará da Serra & 01 & 4,76 \\
\hline Colider & 01 & 4,76 \\
\hline TOTAL & $\mathbf{2 1}$ & $\mathbf{1 0 0}$ \\
\hline
\end{tabular}

Fonte: Nez (2014).

Para análises e reflexões aprofundadas, é preciso relembrar que a IES possui treze campi e que o recorte escolhido para esta pesquisa representou oito unidades acadêmicas, $61,5 \%$ do total. No quadro destaca-se que, levando-se em consideração a especificidade da área física construída constante no anuário (2012), dos três maiores campi (Cáceres, Tangará da Serra e Pontes e Lacerda) a maior quantidade de entrevistados foi na sede $(33,33 \%)$. 
Dessas três unidades, apenas o campus de Pontes e Lacerda não foi contemplada nesta pesquisa de campo.

Com relação à amostra dos líderes de grupos foi delineada a partir do catálogo de grupos (2010). Através dos dados foi possível inferir que seis líderes $(28,5 \%)$ eram do sexo feminino, e o restante masculino (quinze - 71,5\%). Ainda detalhando a caracterização dos entrevistados sobre a titulação acadêmica, estão distribuídos da seguinte maneira: quatro mestres $(19 \%)$, treze doutores $(62 \%)$ e o restante (quatro - 19\%) pós-doutores.

Sobre às áreas do conhecimento contempladas assinalam-se: Engenharias, Ciências Exatas e da Terra, Ciências Biológicas e Ciências da Saúde. Todos os respondentes possuem grupo de pesquisa cadastrado no Diretório de Grupos de Pesquisa no Brasil, organizado pelo Conselho Nacional de Desenvolvimento Científico e Tecnológico (CNPq) certificados pela Unemat.

A entrevista utilizada tinha um extenso rol de questões que tratavam sobre a temática da pesquisa e da Pós-graduação na IES, entre elas, uma solicitava aos líderes opiniões relativas à estrutura multicampi, além de abarcar a discussão relacionada à gestão universitária deste modelo institucional. O restante dos questionamentos buscavam fundamentalmente analisar as políticas e as práticas de pesquisa na Unemat.

No que diz respeito à multicampia, as respostas caminharam para esclarecimentos que podem ser verificados na tabela que segue:

Tabela 02 Sobre a estrutura multicampi da Unemat

\begin{tabular}{c|c|c}
\hline \multicolumn{1}{c|}{ RESPOSTAS ENUNCIADAS } & $\begin{array}{c}\text { QUANTIDADE DE } \\
\text { RESPONDENTES }\end{array}$ & $\begin{array}{c}\text { PORCENTAGEM } \\
\mathbf{( \% )}\end{array}$ \\
\hline CATEGORIA OPERACIONALIDADE: & & $\mathbf{4 3}$ \\
\hline$\bullet$ Articulação dos grupos & 05 & 23,9 \\
\hline$\bullet$ Descentralização de decisões & 02 & 9,5 \\
\hline$\bullet$ Fomento de parcerias & 01 & 4,8 \\
\hline$\bullet$ Isonomia entre os campi & 01 & 4,8 \\
\hline CATEGORIA SOLUÇÕES: & & $\mathbf{5 7}$ \\
\hline$\bullet$ Uso da tecnologia & 06 & 28,5 \\
\hline$\bullet$ Divisão da instituição & 01 & 4,7 \\
\hline Não responderam & 05 & 23,8 \\
\hline TOTAL & $\mathbf{2 1}$ & $\mathbf{1 0 0}$ \\
\hline
\end{tabular}

Fonte: Adaptado de Nez (2013).

A categoria operacionalidade incluiu proposições afirmativas sobre a multicampia como possibilidade de articulação dos grupos de pesquisa $(23,9 \%)$, descentralização de decisões administrativas $(9,5 \%)$, fomento de parcerias entre os pesquisadores da Unemat e de 
outros centros financiadores de projetos $(4,8 \%)$, além da isonomia entre os campi $(4,8 \%)$. Todos esses elementos corroboram para a consolidação da pesquisa na instituição e permitem perceber os pontos satisfatórios de uma universidade com estrutura multicampi. Os dados representaram $43 \%$ das respostas dos líderes de grupos.

Partindo dessas constatações coletadas na análise de conteúdo das entrevistas pontuase que existem vantagens no modelo multicampi sublimadas na categoria operacionalidade, que funcionam como pontos positivos das IES multicampi. Um dos ex-pró-reitores também concorda esclarecendo que: "eu acho que os pontos positivos superam os negativos!" (PR02). Outro respondente salienta que: "eu acho que uma das riquezas da Unemat é essa, ser multicampi! Essa capilaridade.... A gente tem essa oportunidade de ter um universidade multicampi, que outros não tem!" (PR05).

Em contrapartida, em relação a categoria soluções para as dificuldades das universidades multicampi, os respondentes acabaram pressupondo a existência de problemas envolvendo distâncias e deslocamento, sinalizando como solucioná-los. Os dados coletados indicaram a utilização das tecnologias $(28,5 \%)$ enquanto alternativa para superação das fronteiras geográficas entre os campi. Entre as sugestões, que contabilizam 57\%, um destaque vai para a utilização de teleconferência para reuniões, encontros e workshops, tanto relacionados à gestão universitária quanto à parte pedagógica.

A título de fechamento teórico-analítico, considera-se que existem prerrogativas positivas no modelo multicampi. Entretanto, a dispersão geográfica das unidades acadêmicas cria impasses de natureza administrativa e pedagógica, além da dificuldade de comunicação entre os campi, que se torna o nó da questão em detrimento das grandes extensões territoriais envolvidas. Ainda sobre a gestão, um ex-pró-reitor pontua que: “eu acho que talvez a forma da administração e de gerenciamento, esse sim, seja um complicador [...]” (PR03).

Vale ressaltar que para um dos líderes de grupo de pesquisa entrevistado, a estrutura multicampi foi criada dentro de uma política de Estado. "A universidade como órgão do Estado! Foi gestado dentro da política do Estado, e tinha uma política clara para cumprir". Hoje, acredita que é preciso "[...] pensar num planejamento de onde quero chegar como instituição. Traço um plano de ação pra atingir esse objetivo institucional mais amplo que tem a ver diretamente com papel da instituição para a sociedade" (LG04).

Em tempo e para aprofundar reflexões sobre a multicampia, é possível comentar ainda sobre a Pós-graduação Stricto Sensu na Unemat que, conforme elucubrações a partir da análise do quadro 02 é fruto de uma longa caminhada. Iniciou-se com o processo de 
credenciamento da IES, passando pela articulação e organização dos Programas, sobrepondose às ações regulatórias realizadas pela Pró-reitoria de Pesquisa e Pós-graduação que desembocaram na atual situação.

Especificamente sobre a oferta de cursos os dados oferecem inúmeras reflexões detém-se aqui em dois elementos principais que se relacionam com a discussão realizada neste estudo e sobre a gestão universitária: a interdisciplinaridade (fundamento das redes de pesquisa) e a territorialidade. ${ }^{7}$ Quanto ao primeiro, revela-se a existência de posturas interdisciplinares na Pós-graduação, valendo-se das seguintes constatações: existência de um programa que possui abordagem interdisciplinar; e, outro que tem característica multicampi. Com relação ao programa que possui uma perspectiva interdisciplinar ${ }^{8}$, é o de número 01 , coincidentemente o primeiro mestrado registrado na IES, sendo então o mais antigo.

No que tange exclusivamente ao segundo elemento analítico e que também dá suporte às análises realizadas neste estudo, enfatiza-se que há programas que abarcam docentes de outros campi para aulas e orientação. Um exemplo é o mestrado 04, que segundo dados coletados nas entrevistas com os líderes de grupos que exercem atividades nesse Programa e com a Pró-reitoria de Pesquisa e Pós-graduação, possui docentes dos campi de Cáceres, Pontes e Lacerda, Alto Araguaia e Sinop. Isso concretiza a possibilidade de construção de uma proposta de integração territorial a partir da ligação das unidades acadêmicas que estão geograficamente isoladas, incrementado a construção de redes de pesquisadores.

Outra análise basilar é o desdobramento verificado no mestrado 07 que tem como espaço institucionalizado de suas atividades três campi da Unemat. Essa proposta atende ao princípio da integração e da caracterização de universidade interiorizada caso específico da IES analisada, além disso, gera-se uma postura pró-ativa para as redes retornando assim ao primeiro elemento (interdisciplinaridade). O programa foi condicionado à multicampia e foi aceito pela Coordenação de Aperfeiçoamento de Pessoal de Ensino Superior (CAPES) recebendo a melhor avaliação de todos os mestrados (conforme pode ser observado no quadro 02). Talvez essa característica possa ter sido um dos definidores dessa avaliação qualificada. Esse tipo de mestrado poderia ser utilizado pela IES como propulsor de programas que pudessem ampliar o escopo para outras regiões do Estado.

\footnotetext{
${ }^{7}$ Ver mais sobre o tema transversal que fundamentou análises nesse estudo em Santos (1988, 1996, 2001 e 2006).

${ }^{8}$ Em análise de conteúdo complementar realizada na pesquisa documental do acervo específico deste Programa foi perceptível que a interdisciplinaridade é conceituada como a "interação entre os diversos saberes". Além disso, destaca-se que o objetivo deste mestrado acadêmico é "formar profissionais, oriundos de diversos campos do conhecimento", buscando "uma abordagem interdisciplinar".
} 
É cabível comentar à guiza de fechamento analítico do estudo de caso da Unemat que existem inúmeras vantagens na utilização da estrutura multicampi, porém o grande desafio é a superação das distâncias geográficas com o uso das tecnologias para o avanço da articulação dos campi. Conforme informação concedida pela Assessoria da Pró-reitoria de Administração, a IES está trabalhando para concretizar ações de suporte de rede para as teleconferências e demais aplicativos necessários. A previsão é que para os próximos anos, isso esteja parcialmente solucionado e faça frente às atividades a serem desenvolvidas em seu gigante espaço territorial.

\title{
6 CONSIDERAÇÕES FINAIS
}

\begin{abstract}
A universidade não está fora da história de um país; tampouco é toda a história; mas por ela 'passa' a história do país e do povo e ela participa da história, da vida; neste sentido, é aspiração humana, tentativa, ensaio, verificação, drama e desenlace, tarefa comunitária, trabalho de homens que querem se expressar como homens; fato humano que nenhuma lei poderá abolir e que se expressará muitas vezes apesar da lei.

Ela é uma realidade que fala. Deixemo-a, portanto, falar e tratemos de escutá-la, não no que queremos ou no que nos convém, mas no que ela nos quer dizer. (LEYENDECKER, 1974, p. 15 - grifo do autor).
\end{abstract}

A partir do levantamento bibliográfico e documental realizado com vistas à discussão acerca da expansão através da estrutura multicampi na Unemat, e a tentativa de buscar alternativas que impliquem em encaminhamentos que melhorem o seu desenvolvimento, indica-se que a IES encontra-se numa situação emblemática por conta das questões geográficas, conforme explicitado pelos respondentes da pesquisa de campo.

Ao mesmo tempo em que hoje a Unemat constitui-se numa referência para a sociedade na formação de profissionais nas diferentes áreas do conhecimento, leva às regiões o crescimento profissional através dos Programas de Pós-graduação. Essas ações a torna extremamente importante para a interiorização e acesso da/na Educação Superior no Estado. Tal condição faz dessa IES a promotora de interconectividade e interdependência dos atores sociais na construção/socialização do conhecimento científico, na sistematização do saber e na valorização da diversidade cultural. Porém, possui problemas estruturais e com relação à gestão universitária.

Ao longo do aporte teórico caracterizou-se a Unemat enquanto instituição multicampi que mediante a sua presença em um significativo número de município em Mato Grosso proporciona o atendimento à regionalidade. Assim, como IES integrada à comunidade, torna- 
se agente de transformação social, tendo como foco a promoção do desenvolvimento científico, tecnológico, artístico e cultural, visando a melhoria da qualidade de vida da população, preocupando-se com o desenvolvimento econômico e social da região. Da inserção territorial da estrutura multicampi (treze campi) emergem problemáticas geradas pelas distâncias geográfica que geram desafios da/na gestão.

Importa saber é claro como será o desenvolvimento vindouro da Unemat no que diz respeito à essas provocações emergenciais da gestão universitária. Cunha (2001) alerta que as IES devem se voltar para o futuro, refletindo e antecipando as possibilidades de organização política e social, compreende que não é uma "ilha de neutralidade", mas que suas alternativas estão imbricadas na estrutura sócio-política-econômica do país e da região onde está inserida, nesse caso no Estado de Mato Grosso.

As evidências ao longo deste estudo teórico-prático revelam que a articulação entre as dimensões acadêmicas, organizacionais e espaciais atua como uma variável importante para com a funcionalidade do modelo universitário multicampi. Diante dos resultados obtidos, constatou-se que a gestão de uma universidade com modelo multicampi, apresenta dois elementos estruturantes: a organização acadêmica; e a dimensão regional, que atendem as comunidades que nem sempre possuem acesso à Educação Superior.

Como visto no referencial teórico algumas das definições da multicampia potencializam a ideia de quantidade de unidades físicas de uma universidade. A Unemat através de sua expansão desenhada a partir da década de noventa, atende fielmente à caracterização de uma instituição multicampi. É notório que existem inúmeras vantagens na utilização da estruturação multicampi e que seu desafio é a superação das extensões territoriais com o uso das tecnologias em direção à articulação institucional.

Entendeu-se nessa investigação que as IES multicampi, por adentrarem regiões longes dos grandes centros urbanos, podem ser uma possibilidade de integração da universidade com a comunidade em sua exímia função social de harmonizar o desenvolvimento local onde se encontra inserida, contudo, entrelaçando-se aos movimentos globais da sociedade.

Pode-se, concluir finalmente que ser IES multicampi, não é dispor apenas de uma estrutura diferenciada, como também não se caracteriza exclusivamente, pelo seu aspecto organizacional multinucleado. Em sendo desta forma, identificar esse modelo só por uma desconcentração de espaço físico é utilizar um indicativo frágil. Necessita-se ampliar essa definição considerando a riqueza que se configura nas particularidades das dimensões funcionais, espaço-temporais e regionais. 


\section{AGRADECIMENTOS}

Há um agradecimento especial, à orientadora da tese que originou essas reflexões, Profa. Dra. Maria Estela Dal Pai Franco, da Universidade Federal do Rio Grande do Sul (UFRGS), pelo apoio e considerações ao longo do desenvolvimento desta investigação.

\section{REFERÊNCIAS}

ANUÁRIO Estatístico da UNEMAT 2012. Pró-Reitoria de planejamento e desenvolvimento institucional. Disponível em: http://www.novoportal.unemat.br. Acesso em: 20 jul. 2012.

BAMPI, A. C.; DIEL, J. O. O modelo multicampi de universidade e suas relações com a sociedade. XIII Coloquio de Gestión Universitaria en Américas: rendimientos académicos y eficacia social de la universidad. Florianópolis: Universidade Federal de Santa Catarina (UFSC), 2013.

BARDIN, L. Análise de conteúdo. 4. ed. Lisboa: Edições 70, 1977.

BOAVENTURA, E. M. Tempo de educar: pronunciamentos sobre educação e cultura, 19841985. Salvador: Secretaria de Educação e Cultura, 1987.

BOURDIEU, P. Homo academicus. Trad. Ione Ribeiro Valle e Nilton Valle. Florianópolis: UFSC, 2011.

BRASIL. Diretrizes gerais do decreto 6096 - REUNI: Reestruturação e expansão das universidades federais. Disponível em:

http://portal.mec.gov.br/sesu/arquivos/pdf/diretrizesreuni.pdf. Acesso em: 19 fev. 2012.

BUARQUE, C. A aventura da universidade. São Paulo: UNESP, Rio de Janeiro: Paz e Terra, 1994.

CABRAL NETO, A. Política de acesso e permanência de alunos da escola pública à UFRN: desafios e perspectivas. RISTOFF, D.; SEVEGNANI, P. Democratização do campus. Brasília: Instituto Nacional de Estudos e Pesquisas Educacionais Anísio Teixeira, 2006.

CASTELLS, M. A era da informação: economia, sociedade e cultura. V. 1. 5. ed. São Paulo: Paz e Terra, 2001.

CATÁLOGO dos grupos de pesquisa. Cáceres: UNEMAT, 2010.

CHAUÍ, M. Escritos sobre a universidade. São Paulo: Unesp, 2001.

CUNHA, L. A. Dimensões sociais da gestão universitária. VELLOSO, J. (org.). O ensino superior e o MERCOSUL. Rio de Janeiro: Garamond, 1998. 
CUNHA, M. I. Universidade e pesquisa: ensaio do futuro. LINHARES, C., FAZENDA, I. \& TRINDADE, V.(orgs.). Os lugares dos sujeitos na pesquisa educacional. 2. ed. Campo Grande: UFMS, 2001.

DIDRIKSSON, A. Contexto global y regional de la educación superior en América Latina y el Caribe. GAZZOLA, A. L.; DIDRIKSSON, A. (orgs.). Tendencias de la educación superior en América Latina y el Caribe. Caracas: IESALC/UNESCO, 2008. Disponível em:

http://www.iesalc.unesco.org.ve/index.php?option=com content\&view $=$ article $\&$ id $=2 \&$ Itemid =408\&lang=es Acesso em: 04 ago. 2011.

FAVERO, O.; OLIVEIRA, R. A. Estados da arte e disseminação da pesquisa educacional: nota dos organizadores Em Aberto. Brasília, v. 25, n. 87, jan./jun. 2012, p. 189-191.

FIALHO, N. H. Universidade multicampi. Brasília: Autores Associados: Plano, 2005.

FRANCO, M. E. D. P. Construção de conhecimento acerca da qualidade na gestão da educação superior. MOROSINI, M. C. (org.). Qualidade na educação superior: reflexões e práticas investigativas. V. 3. Porto Alegre: EDIPUCRS, 2011.

FRANCO, M. L. P. B. Análise do conteúdo. Brasília: Liber Livro, 2008.

GAMBOA, S. S. Quantidade-qualidade: para além de um dualismo técnico e de uma dicotomia epistemológica. SANTOS FILHO, J. C.; GAMBOA, S. S. (orgs.) Pesquisa educacional: quantidade-qualidade. São Paulo: Cortez, 1995.

GIANOTTI, J. A. A universidade em ritmo de barbárie. São Paulo: Brasiliense, 1986.

GUERRA, I. C. Pesquisa qualitativa e análise de conteúdo: sentidos e formas de uso. Cascais: Principia, 2008.

HISTÓRICO. Disponível em: http://www.unemat.br/. Acesso em: 20 fev. 2011.

HOUAISS, A. \& VILLAR, M. S. Dicionário da língua portuguesa. Rio de Janeiro: Objetiva, 2009.

LAUXEN, S. L. Universidade multicampi. In MOROSINI, M. (coord.). Enciclopédia de pedagogia universitária: glossário. V. 2. INEP/MEC, 2006.

LEYENDECKER, E. Universidad y dependencia. Buenos Aires: Guadalupe, 1974.

LIPOVETSKY, G. Os tempos hipermodernos. Trad. Mario Vilela. São Paulo: Barcarolla, 2004.

MACHADO CUNHA, M. O trabalho dos professores e a Universidade do Estado de Mato Grosso em Sinop/MT na década de 1990: o sentido do coletivo. Tese de Doutorado, Programa de Pós-graduação em Educação da Universidade Federal do Rio Grande do Sul (UFRGS), Porto Alegre, 2010. 
MOROSINI, M. C. Estado do conhecimento sobre internacionalização da educação superior: conceitos e práticas. Educar. Curitiba, n. 28, 2006b. p. 107-124.

NEVES. C. E. B. Ensino superior no Brasil: expansão, diversificação e inclusão. Congresso da Associação de Estudos Latino Americanos (LASA). São Francisco/Califórnia: 2012.

NEZ, E. Alternativa tecnológica para superação das fronteiras geográficas nas instituições multicampi. V Seminário de informática na educação. v.II. Sinop: UNEMAT, 2013. p.113.

Em busca da consolidação da pesquisa e da pós-graduação numa universidade estadual: a construção de redes de pesquisa. Tese de Doutorado em Educação da Universidade Federal do Rio Grande do Sul (UFRGS), Porto Alegre, 2014.

.; SILVA, R. T. P. Democratização no ensino superior brasileiro: o caso das universidades multicampi. VII Congresso iberocamericano de docência universitária. Ensino superior: inovação e qualidade na docência. Porto: Universidade do Porto, 2012a.

.; SILVA, R. T. P. Levantamento da multicampia nas universidades brasileiras: um paralelo entre as regiões sul e centro-oeste. IX ANPED SUL Seminário de Pesquisa em Educação da Região Sul: A Pós-graduação e suas interlocuções com a Educação Básica. Caxias: UCS, 2012b.

PLANO de desenvolvimento do Estado de Mato Grosso MT+20. Disponível em: http://www.seplan.mt.gov.br/arquivos/A_531f19ce5827d5ea5462014de666c3b8Versao\%20T ecnica\%20PD\%20MT.pdf. Acesso em: 09 abr. 2013.

PLANO de desenvolvimento institucional 2008/2014. (2008). Cáceres: 2008. Disponível em: http://www.unemat-net.br/. Acesso em: 23 set.

PRETTO, N. L. (org.). Globalização e educação: mercado de trabalho, tecnologias de comunicação, educação à distância e sociedade planetária. 2. ed. Ijuí: Unijuí, 2000.

SANTOS, M. Natureza do espaço: técnica e tempo. Razão e emoção. 4. ed. São Paulo: USP, 2006.

. Metamorfoses do espaço habitado: fundamentos teórico e metodológico da geografia. São Paulo: Hucitec, 1988.

. Por uma outra globalização: do pensamento único à consciência universal. 6. ed. Rio de Janeiro: Record, 2001.

Técnica, espaço e tempo: globalização e meio técnico-científico informacional. 2. ed. São Paulo: Hucitec, 1996.

SILVA, T. T.; GENTILI, P. (orgs.). Escola SA: quem ganha e quem perde no mercado educacional do neoliberalismo. Brasília: CNTE, 1996. 
ZABALZA, M. A. O ensino universitário: seu cenário e seus protagonistas. Porto Alegre: Artmed, 2004.

ZATTAR, N. B. S. UNEMAT 30 anos: pelos caminhos de Mato Grosso. Cáceres: UNEMAT, 2008.

., TAVARES, D. \& ARTIOLI, L. B. F. (orgs.). Unemat para todos: gestão 20022010. Cáceres: Universidade do Estado de Mato Grosso, 2010.

WANDERLEY, L. E. W. O que é universidade? 2. ed. São Paulo: Brasiliense, 1984. 